\title{
Work-Family Experience: Its Relation with Self-Identity
}

\author{
Azelin Aziz*, Nor Azimah Chew Abdullah, Awanis Ku Ishak, Siti Norasyikin Abdul Hamid \\ School of Business Management (SBM), Universiti Utara Malaysia, Sintok, Kedah, Malaysia \\ *Corresponding author: azelin@uum.edu.my
}

\begin{abstract}
Many studies have examined the manner in which demands in work and family roles impact work-family experiences. Given that gender-role somewhat shapes an individual's self-identity, this study suggests that an individual's experience of favourable or unfavourable work-family experience depends on his or her self-identity. More specifically, this study aims to investigate whether the compatibility between one's self-identity and the role in which one is engaged in, results in a buffering effect or a detrimental effect of role demand on the work-family balance experience.
\end{abstract}

Keywords: Work-family interface, self-identity, cross-culture

(C) 2016 Penerbit UTM Press. All rights reserved

\subsection{INTRODUCTION}

Increased interest by researchers to study the work and family interrelationship is primarily attributable to the global trend of increased participation of women, dual-career earners and single-parent families in the workforce (Aryee, Srinivas \& Hwee, 2005; Hansen, 1991). This signifies that the majority of workforces are currently bearing multiple roles in daily life-juggling between work and family.

In the literature, the majority of work-family studies are populated in the West (Cohen \& Kirchmeyer, 2005; Poelmans et al., 2003). This is reasonable, given that the changes in workforce composition are first experienced by developed countries. However, the characteristic present in non-Western settings, which has a more traditional gender-role ideology as compared to the West, is believed to have made combining the work and family roles more challenging. In this setting, running the household and child-caring are primarily performed by women. Hence, although working, women are also the primary household managers. This situation warrants a study on the work-family interrelationship among non-Western people. Malaysia is among the settings that represent this situation (Noor, 1999).

In Malaysia, the changes in workforce composition are apparent. As seen in the department of statistics (2015) report, over five million members of the Malaysian workforce is composed of women. More than half of these women are married (63.1\%), and over 7\% are either widowed or divorced (see Table 1). It is evident that the majority of the Malaysian workforce is juggling between work and family roles. As such, this poses the question of whether they are achieving a balance in their work-family lives.

Table 1 Number and percentage distribution of employed labor force by marital status, 2015

\begin{tabular}{|l|l|l|l|}
\hline & Total & Male & Female \\
\hline Total & $14,067.7$ & $8,691.1$ & $5,376.7$ \\
$(\%)$ & 100.0 & 100.0 & 100.0 \\
\hline Never married & $4,608.2$ & $3,007.7$ & $1,600.6$ \\
& 32.8 & 34.6 & 29.8 \\
\hline Married & $8,901.7$ & $5,509.7$ & $3,392.0$ \\
& 63.3 & 63.4 & 63.1 \\
\hline Widowed & 300.3 & 85.9 & 214.5 \\
& 2.1 & 1.0 & 4.0 \\
\hline Divorced/Separated & 257.5 & 87.9 & 169.6 \\
& 1.8 & 1.0 & 3.2 \\
\hline \multicolumn{2}{|l}{} \\
\end{tabular}

A balance between the work and family life is commonly termed as work-family balance (WFB). There are many related terms with regards to the interrelationship of work and family life such as work-family conflict and work-family enrichment. The literature is populated with the conflict perspective, which is the negative effect of combining both work and family roles. This study focuses on a positive side of 
combining work and family, namely, the balance perspective. In specific, this study aims to examine the effects of role demands on workfamily balance experience, taking into account the gender-role related issue.

\subsection{LITERATURE REVIEW}

\section{A Balanced Work-Family Life}

A balanced work-family, also termed as work-family balance (WFB), has been defined in various ways in the related literature. For example, some scholars define it from the equality perspective (e.g. Kirchmeyer, 2000; Greenhaus et al. 2003): balance is perceived when equal input and outcomes are observed across domains. Among the critiques from this perspective is that there is little evidence in the literature which suggests that people seek "equality" in their work and family lives (Grzywacz \& Carlson, 2007). For instance, those who have a domestic helper at home may not mind if they need to spend longer hours at work, as opposed to those who do not.

On the other hand, the most widely held interpretation of WFB is the lack of conflict or interference between work and family roles (Frone, 2003). Balance is considered to be achieved when there is lack of conflict between the two domains. Although somewhat reasonable, the mere absence of conflict may not adequately capture the positive aspects of work-family interface that is likely to contribute to a balanced work-family arrangement (Frone, 2003). As such, scholars have started to propose a more comprehensive definition of WFB which incorporates the positive and negative dimensions of work-family interface. For example, Clark (2001) defined WFB as "satisfaction and good functioning at work and at home with a minimum of role conflict" (p.349).

On the whole, the various definitions of balance, although somewhat vary, actually depict a similar connotation of balance that is the successful management and juggling of multiple roles, which is in this case work and family.

In the work-family literature, studies on the balance perspective in non-Western settings are relatively fewer as opposed to the conflict perspective (e.g. Lu, Gilmour, Kao \& Huang, 2006; Noor, 2004). Given that, the majority of works in this area follow the conflict perspective, papers that are conflict-focused are also incorporated in the reviews of the present study.

\section{Linking Gender-Role And Self-Identity}

Similar factors are seen to influence the various work-family experience, be it the conflict or balance experiences. More specifically, factors that reside in the work aspect and the family aspect have been widely studied. The work factor includes the number of hours worked, workload, days worked per week, overtime and work schedule, while the family aspect comprises factors such as the number and age of dependents in the household, hours spent on household chores, childcare hours and spouse employment (Lu, Gilmour, Kao \& Huang, 2006; Lu et al., 2006; Foley, Yue \& Lui, 2005). The demand from both roles, together is termed 'role demand'. Role demands refer to the aspects of roles that require an individual's resources of time, energy, and attention. In some research, the term "role stressor" is alternatively used (Spector et al., 2004). Generally, the findings indicate that increased role demands are potentially detrimental to individual work-family experiences (e.g. Lu, Gilmour, Kao \& Huang, 2006; Spector et al., 2004; Yang et al., 2000).

Nevertheless, some variations in work-family experiences were observed in the literature. More specifically, role demands are seen to have a dissimilar impact on individual work-family experiences. This is more visible when comparison is made across different cultures. For example, comparing British and Taiwanese cultures, Lu et al. (2006) found that there was a stronger relationship between workload and WFC, as well as stronger relationships among sharing household chores and FWC in the British sample than in the Taiwanese sample. Most often, this varying effect was attributed to the differing cultural factors.

In non-Western culture, the gender-role is more traditional. In this setting, even though working, women are still expected to assume the primary role in the household, making the issue of juggling work and family more central, particularly to women in this society.

Gender-role refers to the beliefs and values about the appropriate division of labour between men and women at work and at home (McHugh \& Frieze, 1997). It is often conceptualised on a continuum ranging from traditional to non-traditional or egalitarian. The traditional gender role holds the work role for women to be secondary to domestic and maternal roles. The role of a mother is highly valued, and the home is primarily the woman's responsibility. In contrast, cultures with egalitarian gender-roles expect men and women to invest more equally in domestic and family economic roles (Emrich, Denmark \& Den Hartog, 2004; Roehling et al., 2005). The egalitarian gender-role is characterised by equal opportunities for both men and women in various life aspects such as education, employment, and sharing of family responsibilities.

The related literature has suggested that gender-role and individual self-identity are somewhat related. When individuals become engaged in their role activities, and these activities become a source of meaning and contribute to their sense of self, they develop identities linked to these corresponding roles, which in this case are either the work-identity or the family-identity.

For instance, in a society with a traditional gender-role, women generally assume the primary role at home for running the household and child-caring. It is believed that women in this type of society would spend relatively more time and energy on household affairs compared to women in an egalitarian society. Thus, having spending lots of time and energy in this domain, women in the traditional gender-role society are believed to have a fairly high attachment to the family role. This means that a larger portion of women's self-identity is tied to this role (i.e. higher family-identity).

In contrast, as women's participation in paid employment is more recognised in an egalitarian society, a greater work-identity would be observed in these women than in the women of a traditional society. In other words, women in a more egalitarian gender-role are believed to have higher work-identity in themselves as opposed to women in traditional gender-roles.

In the present study, an individual's level of self-identity is measured at the individual level regardless of the cultural group that the individual comes from. 


\section{The Moderating Effect Of Self-Identity}

Role identity (i.e. work and family identities) and role salience are related concepts. Those with a high work identity (family identity) place high salience on their work role (family role) and vice versa. Since there exists an observable number of works done on the role salience moderation effect in the work-family literature, these papers are also reviewed to facilitate hypotheses development.

It is observed that role identity has been studied in relation to work-family experiences. For example Greenhaus, Peng, and Allen (2012) and Wayne, Randel and Stevens (2006) examined role identity as a direct predictor to their outcome measures. Greenhaus, Peng and Allen linked role identity with working hours, while Wayne, Randel and Stevens observed its association with work-family enrichment. However, its role as a moderator is less observed in the work-family literature.

As mentioned above, role identity reflects an individual's degree of identification to his or her social roles. The degree of identification will somehow influence the time and energy they devote to this particular role (Stryker \& Serpe, 1994), thus influence the sentiment towards these demands: favourable or unfavourable. However, an investigation on this interaction is not much observed in the work-family literature.

There are 2 views concerning its influence. The first view suggests that when an individual is involved in the role that is compatible with his or her self- identity, the negative impact of demands arising from that role is alleviated. For example, the study by Bagger et al. (2008) examined the interactive effect of family identity salience and family-interfering-with-work (FIW) on two outcome variables: job satisfaction and job distress. Their results showed that individuals who experienced a high level of FIW (a stressor from the family domain) only reported more job distress and less job satisfaction when they were low in family identity salience. This result suggested that when family identity salience is high, the negative impact of FIW on the outcome variables was alleviated.

The second view indicates the opposite, that is, that the impact of role demand is exacerbated when the role an individual is engaged in is compatible with his or her self- identity. For example in Noor's (2004) study which investigated the moderating effect of role salience on the relationship of WFC and two facets of individuals' well-being: job satisfaction and distress. Work role salience exacerbated the negative impact of WIF (a stressor from the work domain) on well-being. Although the study examined the moderated relationship between conflict and well-being, not the relationship between the role demand and work-family experience, it nevertheless indicated that salient role identity might in fact exacerbate the impact of role stressors on outcome measures.

From the above, it is not precisely clear how self-identity interacts with role demands to influence work-family experiences. Given these conflicting views, the non-directional moderating hypotheses are proposed as below.

\section{H1: The relationship between work demand and work-family balance is moderated by individuals' work identity}

\section{H2: The relationship between family demand and work-family balance is moderated by individuals' family identity}

Figure 1 depicts the anticipated relationship between role demands, work-family balance experience and self-identity.

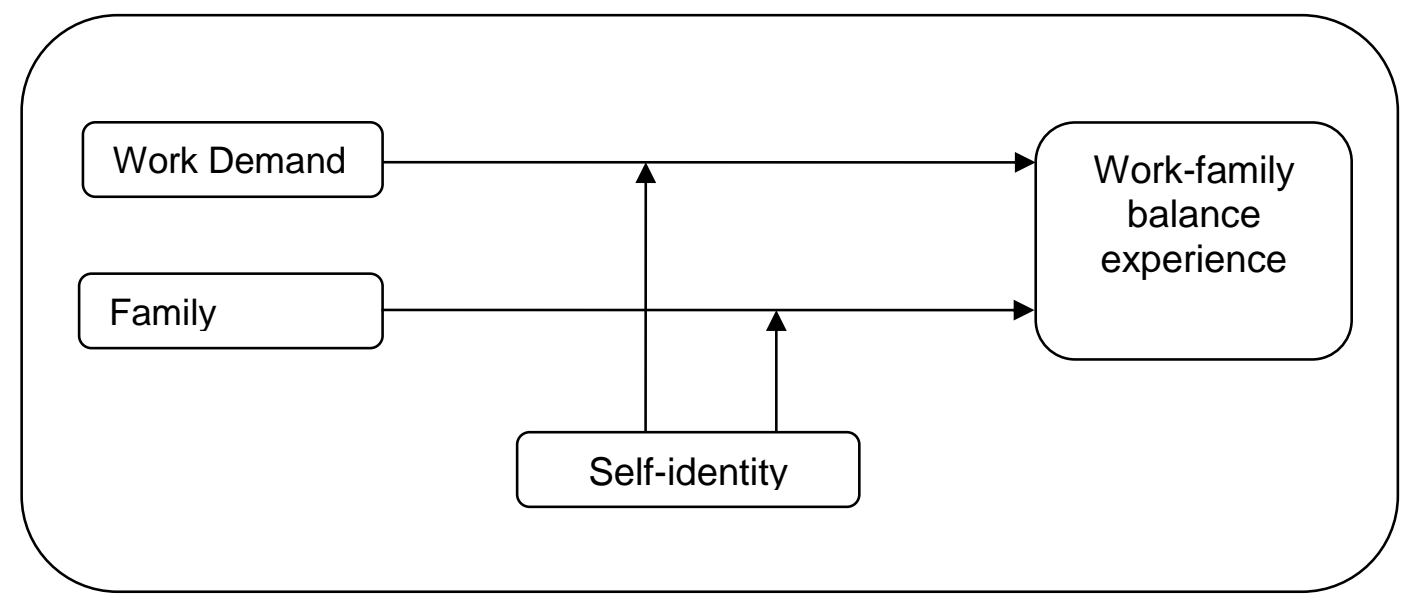

Figure 1 Proposed Research framework

\subsection{CONCLUSION}

This study contributes to the overall understanding of the manner in which self-identity influences one's perceptions of role demands one occupies, which eventually affects their experience of work-family balance. In this study, the aim is to identify whether a buffering or a detrimental effect surfaces when there is a match or compatibility between one's self-identity with the role demands they are engaged in. The finding from this study is believed to be useful for management to better handle job assignment among staff, taking into account their self-identity. In conclusion, the proper administration of the workforce predicts organization effectiveness, and not merely the skilfulness on the technical parts of businesses. 


\section{References}

Aryee, S., Srinivas, E. S., \& Hwee, H. T. (2005). Rhythms Of Life: Antecedents And Outcomes Of Work-Family Balance In Employed Parents. Journal of Applied Psychology, 90(1), 132-146.

Bagger, J., Li, A., \& Gutek, B. A. (2008). How Much Do You Value Your Family And Does It Matter? The Joint Effects Of Family Identity Salience, FamilyInterference-With-Work, And Gender. Human Relations, 61(187-211).

Clark, S. C. (2001). Work Cultures And Work/Family Balance. Journal of Vocational Behavior, 58, 348-365.

Cohen, A., \& Kirchmeyer, C. (2005). A Cross-Cultural Study Of The Work/Nonwork Interface Among Israeli Nurses. Applied Psychology: An International Review, $54(4), 537-567$

Department of Statistics, Malaysia. (2015). Key indicator of the labour market Malaysia, http://www.statistics.gov.my/portal/download_Labour/files/BPTMS/ringkasan_perangkaan_2015.pdf

Emrich, C. G., Denmark, F. L., \& Den Hartog, D. N. (2004). Cross-Cultural Differences In Gender Egalitarianism: Implication For Societies, Organizations, And Leaders. In R. J. House, P. J. Hanges, M. Javidan, P. W. Dorfman \& V. Gupta (Eds.), Culture, Leadership, and Organizations: The Globe Study of 62 societies (pp. 343-394). Thousand Oaks, CA: Sage

Foley, S., Yue, N. H., \& Lui, S. (2005). The Effects Of Work Stressors, Perceived Organizational Support, And Gender On Work-Family Conflict in Hong Kong. Asian Pacific Journal of Management, 22(3), 237-256

Frone, M. F. (2003). Work-family balance. In J.C. Quick \& L.E. Tetrick (Eds.), Handbook of Occupational Health Psychology (pp. 143-162). Washington: APA

Greenhaus, J.H., Peng, A.C., \& Allen, T.D. (2012). Relations Of Work Identity, Family Identity, Situational Demands, And Sex With Employee Work Hours. Journal of Vocational Behavior, 80, 27-37

Greenhaus, J. H., Collins, K. M., \& Shaw, J. D. (2003). The Relation Between Work-Family Balance And Quality Of Life. Journal of Vocational Behavior, 63(3), 510531.

Grzywacz, J. G., \& Carlson, D. S. (2007). Conceptualizing Work Family Balance: Implications For Practice And Research. Advances in Developing Human Resources, 9, 455-471.

Hansen, G. L. (1991). Balancing work and family: A Literature And Resource Review. Family Relations, 40(3), 348-353.

Kirchmeyer, C. (2000). Work-life initiatives: Greed or Benevolence Regarding Workers' Time. In C. L. Cooper \& D. M. Rousseau (Eds.), Trends in Organizational Behavior (Vol. 7, pp. 79-93). West Sussex, UK: Wiley.

Lu, L., Gilmour, R., Kao, S. F., \& Huang, M. T. (2006). A Cross-Cultural Study Of Work/Family Demands, Work/Family Conflict And Wellbeing: The Taiwanese vs British. Career Development International, 11(1), 9-27.

McHugh, M. C., \& Frieze, I. H. (1997). The Measurement Of Gender-Role Attitudes: A Review And Commentary. Psychology of Women Quarterly, 21, 1-16

Noor, N. M. (1999). Roles And Women's Well-Being: Some Preliminary Findings From Malaysia. Academic Research Library, 41(3/4), $123-145$.

Noor, N. M. (2004). Work-Family Conflict, Work And Family Role Salience, And Women's Well-Being. The Journal of Social Psychology, 144(4), 389-405

Poelmans, S. (2003). The multi-Level 'Fit' Model Of Work And Family. International Journal of Cross-Cultural Management, 3(3), 267-274.

Roehling, P. V., Jarvis, L. H., \& Swope, H. E. (2005). Variations In Negative Work-Family Spillover Among White, Black, and Hispanic American Men and Women: Does ethnicity matter? Journal of Family Issues, 26(6), 840-865

Spector, P. E., Cooper, C. L., Poelmans, S., Allen, T. D., O'driscoll, M., Sanchez, J. I., et al. (2004). A Cross-National Comparative Study Of Work-Family Stressors, Working Hours, And Well-Being: China and Latin America versus the Anglo world. Personnel Psychology, 57(1), 119-142.

Stryker, S., \& Serpe, R. T. (1982). Commitment, identity Salience, And Role Behavior. In W. Ickes \& E. S. Knowles (Eds.), Personality, Role and Social Behavior (pp. 199-218). New York: Springer Verlag

Wayne, J.H., Randel, A.E., \& Stevens, J. (2006). The Role Of Identity And Work-Family Support In Work-Family Enrichment And Its Work-Related Consequences Journal of Vocational Behavior, 69, 445-461

Yang, N., Chen, C. C., Choi, J., \& Zou, Y. (2000). Sources Of Work-Family Conflict: A Sino-U.S. Comparison Of The Effects Of Work And Family Demands. Academy of Management Journal, 43(1), 113-123. 